\title{
Weather based prediction model for beet armyworm (Spodoptera exigua Hubner) in chickpea
}

\begin{tabular}{lll}
\hline Paper received: 18.01 .2018 & Revised received: $12.05 .2018 \quad$ Accepted: 28.06 .2018
\end{tabular}

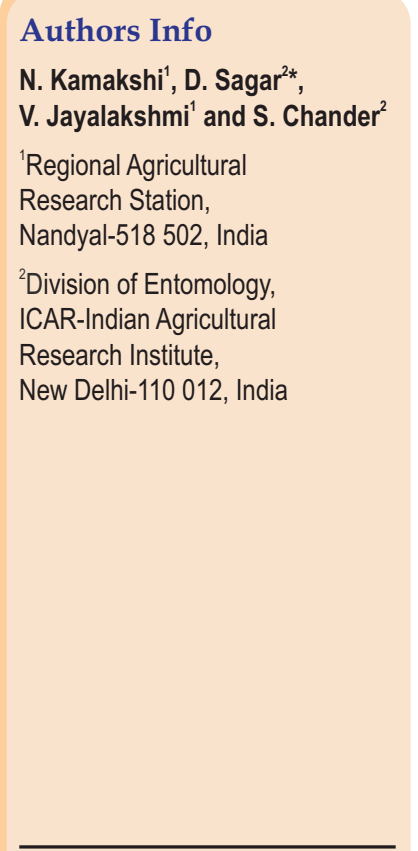

*Corresponding Author Email : garuda344@gmail.com

\section{Edited by \\ Dr. Gundappa}

\section{Reviewed by}

Dr. M. H. Kodandaram

Dr. R.B. Raizada

\section{Abstract}

Aim : The study aimed to develop and validate weather based prediction model for beet armyworm (Spodoptera exigua) population in chickpea through adult catches in pheromone traps.

Methodology : The data on adult trap catches of $S$. exigua were recorded daily and weekly means were computed. Log transformed trap catches data were used for correlation with weather parameters of current week, 1-lag, 2-lag and 3-lag weeks. Thereafter, multiple-linear regression analysis was done and a model was developed. The prediction model of $S$. exigua was validated with the appropriate statistical tools.

Results : Peak incidence of $S$. exigua was recorded during $45^{\text {th }}$ standard meteorological week (SMW) with 15.6 moths per trap per week. Amongst current, 1-lag, 2-lag and 3-lag week weather parameters, the male moth population had significant positive correlation with maximum temperature $\left(T_{\max }\right)$ and minimum temperature $\left(T_{\min }\right)$, and negative correlation with morning relative humidity $\left(\mathrm{RH}_{1}\right)$ of 2-lag week. The sunshine hours/day (SSH) of current week had a significant negative association with S. exigua male moth catches, while the soil temperature (ST) of 2-lag week had highest positive correlation with trap catches. Regression equation was computed by regressing male moth catches of $S$. exigua against weather data of weeks with highest correlation coefficient.
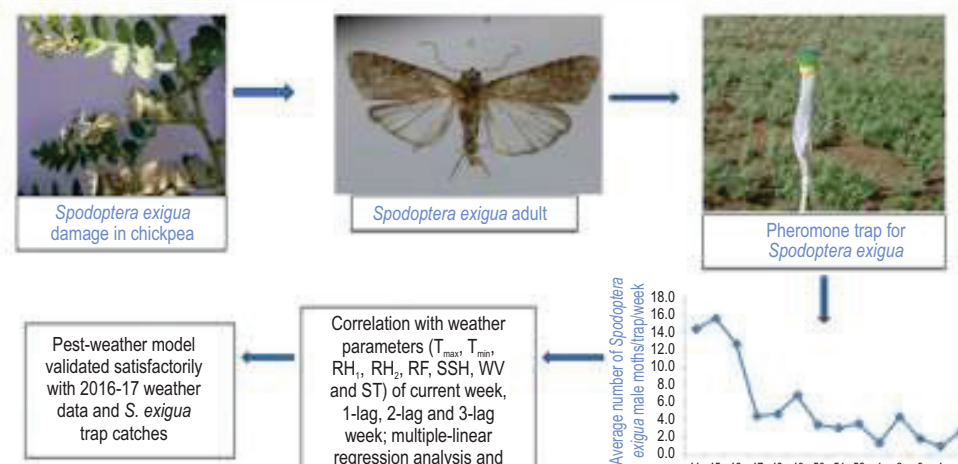

Correlation with weather parameters $\left(T_{\max }, T_{\min }\right.$ $\mathrm{RH}_{1}, \mathrm{RH}_{2}, \mathrm{RF}, \mathrm{SSH}, \mathrm{WW}$ and ST) of current week, 1-lag, 2-lag and 3-lag week; multiple-linear regression analysis and

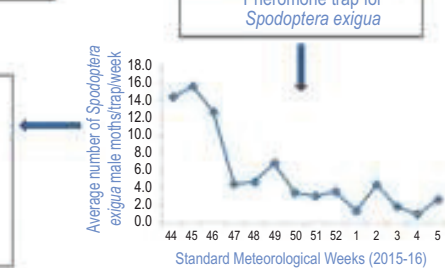

Interpretation : Often, pest-weather models are developed based on current week weather factors. However, it has been witnessed in this study that weather of preceding weeks (up to 3-lag) may also influence the pest population, and thus it needs to be considered for proper understanding of pest dynamics.

Key words: Chickpea, Pheromone trap, Spodoptera exigua, Weather based model

How to cite: Kamakshi, N., D. Sagar, V. Jayalakshmi and S. Chander: Weather based prediction model for beet armyworm (Spodoptera exigua Hubner) in chickpea. J. Environ. Biol., 40, 84-88 (2019). 


\section{Introduction}

Chickpea (Cicer arietinium L.), known as king of pulses is the second most important pulse crop grown globally on an area of 14 million ha across 55 countries, and plays an important role in human nutrition. India is the largest producer of chickpea with a share of about $70 \%$ in area and $67 \%$ production in the world (Dixit et al., 2017). Among the several constraints in chickpea cultivation, insect pests pose greater threat to chickpea production that result in poor yields. Intensive cultivation of chickpea on wide area might result in emergence of new pest problems, while some of the minor pests may assume a serious pest status. As a result of climate change and changes in cropping patterns, the beet armyworm, Spodoptera exigua (Hubner) is emerging as a serious pest of chickpea, especially in Southern India (Jagdish and Sharma, 2017) causing heavy damage to the germinating seedlings and the crop up to the vegetative stage. In severe cases, larvae defoliates the crop completely at early stages of growth (Shankar et al., 2014).

As a leaf feeder, the beet armyworm infestation is higher in chickpea tissues than the chickpea pod borer, $\mathrm{H}$. armigera (Shankar et al., 2013). S. exigua moths have greyish brown forewings and opalescent hind wings with a dark edge. Farmers apply 1-2 sprays of new insecticides which leads to increased cultivation cost, insecticide resistance, health hazards and environmental pollution. Monitoring of pest population and analysis of population trend of the insect pests forms an important component of pest management. In this regard, pheromone traps are the important component in integrated pest management programme for monitoring pest population, facilitating judicious pesticide application at economic threshold level of insect pests. Weather factors such as temperature, rainfall and relative humidity greatly influence the insect pest population (Siswanto et al., 2008). Understanding the pest-weather relationship is of paramount importance for effective pest suppression (Das et al., 2008), maximum temperature, rainfall and evening relative humidity are important factors that influence the rice brown planthopper light trap catches at Mandya, Karnataka (Prasannakumar and Chander, 2014). Kumar et al. (2018) observed that maximum temperature, bright sunshine hours and rainfall are significant weather variables for prediction of aphids incidence in cotton. Reji et al. (2014) reported that weather prevailing during 8-15 days prior to stem borer damage (second lag week) exhibited better correlation with intensity of damage.

As the severity of beet armyworm is greatly influenced by abiotic factors, the present investigation was carried out to develop and validate weather based prediction model for beet armyworm in chickpea by monitoring the adult population of $S$. exigua through pheromone traps.

\section{Materials and Methods}

The experiments were conducted in the chickpea fields of Regional Agricultural Research Station (RARS), Nandyal, Andhra
Pradesh during 2015-16 and 2016-17. The chickpea crop was raised by following the recommended agronomic practices. For monitoring adult moths, Spodoptera exigua lure was procured from Pheromone Chemicals, Hyderabad. The pheromone traps were installed in chickpea fields with the support of poles at $60 \mathrm{~cm}$ height above the ground level @ 10 per hactare. Pheromone trap lures were replaced at 15 days interval. The data on adult trap catches of $S$. exigua were recorded on daily basis, expressed as mean number of male moths per trap per week and normalized by subjecting to square root transformation before using in weather based model development.

Weather data were obtained from the meteorological observatory of RARS, Nandyal, Andhra Pradesh. The relationship between male moth catches and weather parameters viz., maximum temperature $\left(T_{\text {max }}\right)$, minimum temperature $\left(T_{\text {min }}\right)$, morning relative humidity $\left(\mathrm{RH}_{1}\right)$, evening relative humidity $\left(\mathrm{RH}_{2}\right)$, rainfall (RF), sunshine hours (SSH), wind velocity (WV) and soil temperature (ST) of $10 \mathrm{~cm}$ depth of current week, 1-lag, 2-lag and 3-lag weeks was computed using simple correlation co-efficient. Thereafter, multiple-linear regression analysis was carried out by regressing dependent parameter that is male moth catches of $S$. exigua against independent parameters like weekly weather data based on the highest correlation coefficient among current week, 1-lag, 2-lag and 3-lag weeks. Stepwise regression was carried out to evaluate the relative importance of different weather factors based on the coefficient of determination $\left(R^{2}\right)$. The model was validated by selecting the significant factors influencing the trap catches. Model accuracy was evaluated by comparing the root mean-square error (RMSE), mean bias error (MBE) and mean absolute error (MAE) of the predicted and observed data sets of trap catches using the given by Willmott (1982).

\section{Results and Discussion}

First trap catch of $S$. exigua was recorded during $44^{\text {th }}$ standard meteorological week (SMW) and trap catches reached their peak during $45^{\text {th }}$ SMW with 15.6 moths per trap per week, and declined thereafter (Table 1). Earlier, Azidah (2006) monitored the adult population of S. exigua during January 2003 to April 2004 at Sekinchan, Selangor and reported that adults were captured all the time in the studied area, although the numbers fluctuated. The highest (6.63) and lowest (0.65) mean trap catches were recorded during $33^{\text {rd }}$ and $45^{\text {th }}$ SMW, respectively.

Amongst current, 1-lag, 2-lag and 3-lag week weather parameters, the male moth population had significant positive correlation with maximum temperature $\left(r=0.737^{* *}\right)$, minimum temperature $\left(r=0.785^{* *}\right)$ and soil temperature $\left(r=0.887^{* *}\right)$, and significant negative correlation with morning relative humidity $\left(r=-0.544^{*}\right)$ of 2-lag week (Table 2$)$. The sunshine hours per day of current week $\left(r=-0.640^{*}\right)$ had a significant negative association with $S$. exigua male moth catches. On the other hand, the evening relative humidity $(r=0.107)$ of 2lag week and wind velocity of 1 -lag week $(r=0.401)$ showed non-significant positive correlation with trap catch data. 
Table 1 : Pheromone trap catches of Spodoptera exigua in chickpea and weather parameters influencing the population during 2015-16

\begin{tabular}{|c|c|c|c|c|c|}
\hline \multirow{2}{*}{$\begin{array}{l}\text { Standard Meteorological } \\
\text { Week (SMW) }\end{array}$} & \multirow[t]{2}{*}{ Period } & \multirow{2}{*}{$\begin{array}{l}\text { Average number of } \\
\text { male moths per trap per week }\end{array}$} & \multicolumn{3}{|c|}{ Weather parameters } \\
\hline & & & $\begin{array}{l}\mathrm{T}_{\max }\left({ }^{\circ} \mathrm{C}\right) \\
\text { (2-lag week) }\end{array}$ & $\begin{array}{l}\text { WV (Km hr-1) } \\
\text { (1-lag week) }\end{array}$ & $\begin{array}{l}\text { ST }\left({ }^{\circ} \mathrm{C}\right)(2-\text { lag } \\
\text { week) }\end{array}$ \\
\hline 44 & Oct 30- Nov 5 & $14.3(3.85)$ & 35.5 & 4 & 36.00 \\
\hline 45 & Nov 6 - Nov 12 & $15.6(4.01)$ & 35.2 & 4.1 & 35.66 \\
\hline 46 & Nov 13- Nov 19 & $12.6(3.61)$ & 34.1 & 4.5 & 34.40 \\
\hline 47 & Nov 20- Nov 26 & $4.4(2.21)$ & 32.6 & 3.5 & 32.00 \\
\hline 48 & Nov 27- Dec 3 & $4.6(2.26)$ & 30.4 & 4.6 & 28.73 \\
\hline 49 & Dec 4 - Dec 10 & $6.8(2.69)$ & 30.4 & 4.6 & 29.50 \\
\hline 50 & Dec 11- Dec 17 & $3.4(1.96)$ & 31.3 & 4.4 & 29.26 \\
\hline 51 & Dec 18 - Dec 24 & $3.0(1.88)$ & 31.2 & 4.2 & 29.26 \\
\hline 52 & Dec 25- Dec 31 & $3.5(2.0)$ & 32.4 & 3.9 & 29.80 \\
\hline 1 & Jan 1- Jan 7 & $1.3(1.33)$ & 32.1 & 3.3 & 30.40 \\
\hline 2 & Jan 8- Jan 14 & $4.3(2.19)$ & 32.5 & 3.7 & 30.00 \\
\hline 3 & Jan 15-Jan21 & $1.8(1.51)$ & 32.1 & 3.6 & 29.03 \\
\hline 4 & Jan 22-Jan 28 & $0.9(1.19)$ & 31.7 & 4.1 & 28.50 \\
\hline 5 & Jan 29- Feb 4 & $2.6(1.75)$ & 30.3 & 3.7 & 28.70 \\
\hline
\end{tabular}

Figures in the parentheses are $\sqrt{ }(x+0.5)$ transformed values.

While, the rain fall of 2-lag week ( $r=-0.147)$ showed nonsignificant negative association with $S$. exigua male moth catches. On thorough scanning of published literature, it appeared that there were limited reports on the correlation between the adult trap catches of $S$. exigua and weather parameters, so present results were thus discussed based on Helicoverpa armigera trap catches and S. exigua larval studies in relation to weather parameters.

The present findings are in agreement with the earlier reports of Sharma (2005), Pandey et al. (2012) and Sharma et al. (2012), where the minimum and maximum temperature was found to be positively correlated, and relative humidity was negatively correlated with the larval population of $H$. armigera and S. exigua. On contrary to our findings, Azidah (2006) reported that climatic factors did not influence the $S$. exigua moth population, as adult catches showed non-significant association with temperature $(r=0.1556)$, relative humidity $(r=0.265)$ and rainfall $(r=0.08)$.

The correlation studies between $S$. exigua damage in onion crop and weather factors indicated that both the maximum and minimum temperatures had a significant negative correlation, while relative humidity alone showed a significant positive correlation and rainfall did not have any effect on $S$. exigua damage (Arul Kumar et al., 2017). The present findings

Table 2 : Correlation co-efficient between pheromone trap catches of Spodoptera exigua and different weather parameters during 2015-16

\begin{tabular}{lllll}
\hline Weather parameters & Current week & 1-Lag week & 2-Lag week & 3-Lag week \\
\hline $\mathrm{T}_{\max }$ & 0.037 & $0.667^{* *}$ & $\mathbf{0 . 7 3 7 ^ { * * }}$ & $0.685^{* *}$ \\
$\mathrm{~T}_{\min }$ & $0.695^{* *}$ & $0.759^{* *}$ & $\mathbf{0 . 7 8 5 ^ { * * }}$ & $0.687^{* *}$ \\
$\mathrm{RH}_{1}$ & -0.420 & -0.412 & $-0.544^{*}$ & -0.369 \\
$\mathrm{Rh}_{2}$ & 0.062 & 0.096 & $\mathbf{0 . 1 0 7}$ & 0.031 \\
$\mathrm{RF}$ & 0.138 & 0.037 & -0.147 & -0.119 \\
$\mathrm{SSH}$ & $-0.640^{*}$ & -0.209 & 0.036 & -0.022 \\
$\mathrm{WV}$ & 0.290 & 0.401 & 0.017 & -0.199 \\
$\mathrm{ST}$ & 0.523 & $0.849^{* *}$ & $0.887^{* *}$ & $0.799^{* *}$ \\
\hline
\end{tabular}

$\mathrm{n}=14,{ }^{*}$ Significant at $5 \%,{ }^{* *}$ Significant at $1 \%$

$\mathrm{T}_{\max }=$ Maximum temperature $\left({ }^{\circ} \mathrm{C}\right)$

$\mathrm{RH}_{1}=$ Morning Relative humidity (\%)

$\mathrm{RF}=$ Rainfall $(\mathrm{mm})$

WV $=$ Wind velocity $\left(\mathrm{km} \mathrm{hr}^{-1}\right)$
$\mathrm{T}_{\text {min }}=$ Minimum temperature $\left({ }^{\circ} \mathrm{C}\right)$

$\mathrm{RH}_{2}=$ Evening Relative humidity (\%)

$\mathrm{SSH}=$ Sunshine hours (hr day $\left.{ }^{-1}\right)$

$\mathrm{ST}=$ Soil temperature $\left({ }^{\circ} \mathrm{C}\right)$ 


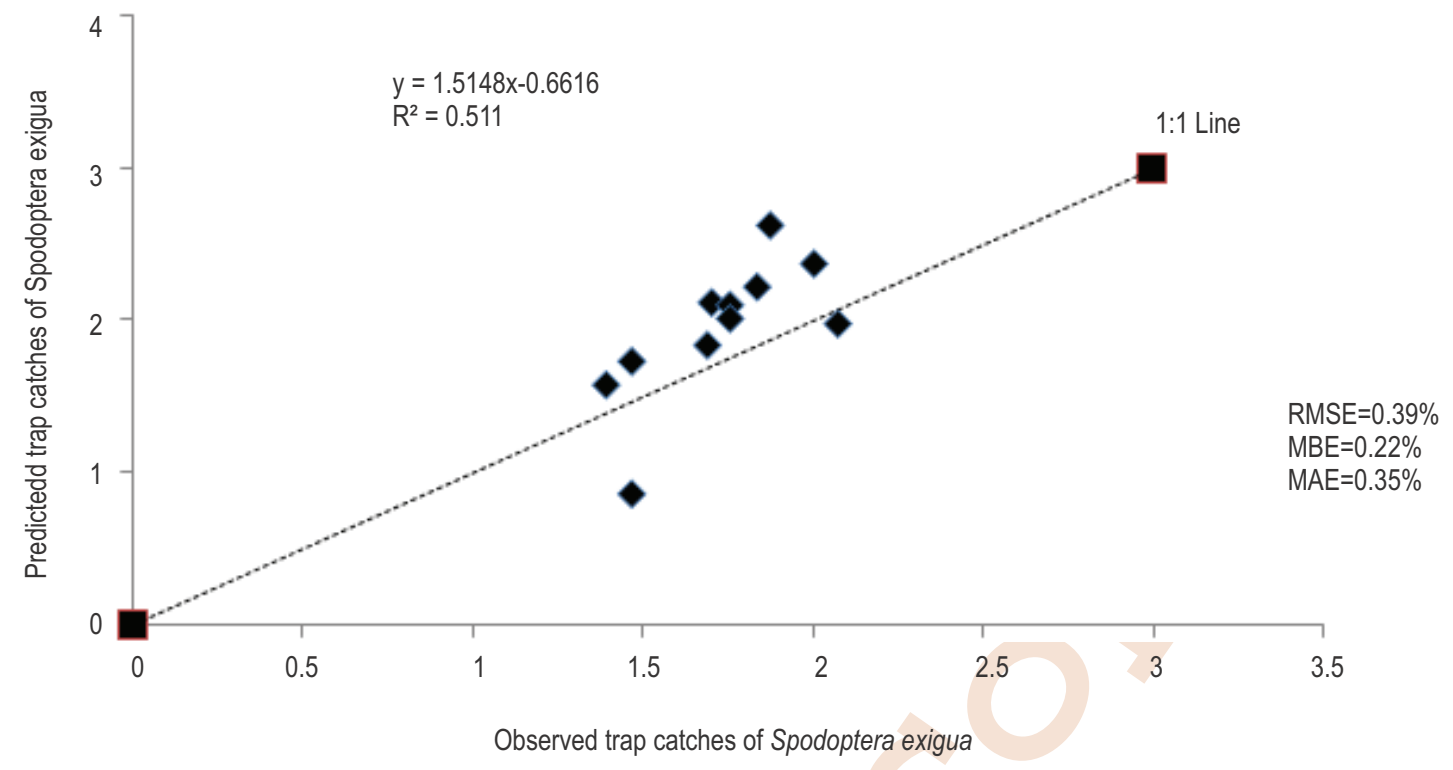

Fig. 1: Validation of Spodoptera exigua weather based model at Nandyal, Andhra Pradesh.

are also in agreement with that of Pandey et al. (2008) wherein minimum temperature and rainfall exerted a negative influence on pheromone trap catches of $H$. armigera. The correlation studies done by Ganai et al. (2017) indicated that larval population of $H$. armigera in marigold had significant positive association with maximum temperature $(r=0.349)$, and significant negative association with morning relative humidity $(r=-0.284)$. The nonsignificant effect was observed between $H$. armigera larval population and evening relative humidity $(r=-0.256)$ and rainfall $(r=-0.174)$, which is in line with the present findings. Regression equation was computed by regressing male moth catches of $S$. exigua (y) as a dependent variable against weather data of weeks with highest correlation coefficient $(\mathrm{x})$ as independent variables. The resultant regression equation for trap catches and weather parameters is as follows :

$$
Y=-8.390-0.065 T_{\max }(2-\mathrm{lag})-0.012 \mathrm{~T}_{\min }(2-\mathrm{lag})-0.014 \mathrm{RH}_{1}
$$
(2-Lag) $+0.015 \mathrm{RH}_{2}(2-\mathrm{Lag})-0.03 \mathrm{RF}(2-\mathrm{Lag})+0.016 \mathrm{SSH}$ (Current) +0.752 WV $(1-\mathrm{Lag})+0.335 \mathrm{ST}(2-\mathrm{Lag})\left(\mathrm{R}^{2}=0.936\right)$

The regression equation, revealed that for every $1^{\circ} \mathrm{C}$ decrease in $T_{\max }$ the male moth catches of $S$. exigua increased by 0.065 per trap per week, while increase in 1 per cent of evening relative humidity increased the trap catches by 0.015 per trap per week. The coefficient of determination $\left(R^{2}=0.936\right)$ indicated that 93.6 per cent variability in male moth catches of $S$. exigua was accounted for different weather parameters.

Stepwise regression was carried out to find the relative importance of different weather factors that influenced $S$. exigua trap catches. The pest-weather model with $T_{\max }$, WV and ST accounted for 93.2 per cent variability in trap catches of $S$. exigua, indicating their significant role.

$$
Y=-7.848-0.14 T_{\max }(2-\mathrm{lag})+0.717 \mathrm{WV}(1-\mathrm{Lag})+0.383
$$

ST (2-Lag) $\left(R^{2}=0.932\right)$

The final model clearly suggested $T_{\max }$ of 2-lag week, WV of 1-lag week and ST of 2-lag week to be important weather parameters influencing male moth catches of $S$. exigua under Nandyal, Andhra Pradesh agroecosystem. $\mathrm{T}_{\max }$ exhibited negative, whereas the wind velocity and soil temperature exhibited the positive relationship with the $S$. exigua trap catches. Conversely, the weather parameters viz., $\mathrm{T}_{\min }, \mathrm{RH}_{1}, \mathrm{RH}_{2}, \mathrm{RF}$ and $\mathrm{SSH}$ did not influence the trap catches of $\mathrm{S}$. exigua. As the pest pupates in the soil, soil temperature at $10 \mathrm{~cm}$ depth of preceding weeks had positive influence on the adult emergence. The model was validated by comparing the observed trap catch data of crop season, 2016-17 with predicted trap catches. The pest-weather model was validated satisfactorily $\left(R^{2}=0.511\right.$, RMSE $=0.39 \%$, $\mathrm{MBE}=0.22 \%$ and $\mathrm{MAE}=0.35 \%$ ) (Fig. 1) with 2016-17 weather data and $S$. exigua trap catches. A positive MBE value indicates that predictions are bigger than the observed values. Similar results witnessed in this study clearly indicated that the prediction model was in the positive direction. Pest-weather models have earlier been developed and validated for rice brown planthopper (Prasannakumar and Chander, 2014), rice yellow stem borer (Prasannakumar et al., 2015), guava fruit fly (Sharma et al., 2015), Helicoverpa armigera in chickpea (Sagar et al., 2017), mustard aphid (Mehnaj et al., 2017) and sucking pests of cotton viz., aphids, thrips and leafhoppers (Kumar et al., 2018). 
Though, the results of the present study are in agreement with most of the previous studies, while it is also varying with few reports, perhaps because the empirical pest-weather models behave in a location-specific manner. Pest-weather model for the $S$. exigua would be helpful in predicting the likely build up of the pest population and timing of management interventions against the pest. However, while developing such pest-weather models, besides considering the current week weather parameters, weather parameters of preceding weeks also need to be considered for model development.

\section{Acknowledgments}

Authors are thankful to the Acharya N. G. Ranga Agricultural University, Guntur, Andhra Pradesh and All India Coordinated Research Project on Chickpea for providing facilities and financial assistance for carrying out the work.

\section{References}

Arulkumar, G., S. Manisegaran, R. Nalini and M. Mathialagan: Seasonable abundance of beet armyworm Spodoptera exigua (Hubner) infesting onion with weather factors in Madurai district of Tamil Nadu. J. Entomol. Zool. Stud., 5, 1157-1162 (2017).

Azidah, A.: Temporal occurrence of Spodoptera exigua (Lepidoptera: Noctuiidae) in Sekinchan, Selangor. J. Entomol., 3, 336-340 (2006).

Das, D. K., K. S. Behera, A. Dhandapani, T. P. Trivedi, N. Chona and P. Bhandari: Development of forewarning systems of rice pests for their management. In: Rice Pest management (Eds.: A. Prakash, A. Sasmal, J. Rao, S. N. Tewari, K. S. Behera, S. K. Singh and V. Nandagopal).Applied Zoologists Research Association, CRRI, Cuttack, pp. 187-200 (2008).

Dixit, G. P., S. Singh, V. Jayalakshmi, A.K. Srivastava and P.M. Gaur: Chickpea improvement-Accomplishments, challenges and strategies. National symposium on Pulses for Nutritional Security and Agricultural Sustainability, IIPR, Kanpur, p. 45 (2017).

Ganai, S. A., H. Ahmad, D. Sharma, N. Khaliq, S. Sharma, R. Kaur and T. Norboo: Effect of abiotic factors on the populations of Pod Borer, Helicoverpa armigera (Hubner) on marigold, Tagetes erecta in Jammu, India. Int. J. Curr. Microbiol. Appl. Sci., 6,181-185 (2017).

Jagdish, J. and H.C. Sharma: Climate change effects on pest population dynamics and pest management. National Symposium on Pulses for nutritional security and agricultural Sustainability, IIPR, Kanpur, pp. 29-36 (2017).

Kumar, A., P. W. Nemade, R. Sharma, R. K. Tanwar, C. Chattopadhyay,
S. S. Wanjari and T. H. Rathod: Statistical forewarning models for sucking pests of cotton in Maharashtra. J. Agrometeorol., 20, 6265 (2018).

Mehnaj, T. A., Y. P. Singh, B.K. Kandpal, K.K. Singh and A.C. Pandey: Forewarning model development for mustard aphid (Lipaphis erysimi Kalt.) at Bharatpur and Hisar. J. Agrometeorol., 19, 334341 (2017).

Pandey, B. M., M. K. Tripathi and Vijay Lakshmi: Monitoring of cotton bollworms through pheromone traps and impact of abiotic factors on trap catch. J. Entomol. Res., 32, 187-192 (2008).

Pandey, B.M., M. K. Tripathi and Vijay Lakshmi: Seasonal incidence of gram pod borer, Helicoverpa armigera (Hub.) on chickpea in Varanasi area. J. Exp. Zool. India, 15, 667-669 (2012).

Prasannakumar, N. R. and S. Chander: Weather-based brown planthopper prediction model at Mandya, Karnataka. J. Agrometeorol., 16, 126-129 (2014).

Prasannakumar, N. R., S. Chander and L. Vijay Kumar: Development of weather based rice yellow stem borer prediction model for the Cauvery command rice areas, Karnataka, India. Cogent Food Agri., 1, 995281 (2015).

Reji, G., S. Chander and K. Kamble: Predictive zoning of rice stem borer damage in Southern India through spatial interpolation of weatherbased models. J. Environ. Biol., 35, 923-928 (2014).

Sagar, D., S. M. Nebapure and S. Chander: Development and validation of weather based prediction model for Helicoverpa armigera in chickpea. J. Agrometeorol., 19, 328-333 (2017).

Shankar, M., H. C. Sharma, T. Ramesh Babu and D. Sridevi: Evaluation of chickpea genotypes for resistance to beet armyworm, Spodoptera exigua. Indian J. Plant Prot., 41, 275-281(2013).

Shankar, M., T. Ramesh Babu, D. Sridevi and H. C. Sharma: Incidence and biology of beet armyworm, Spodoptera exigua in chickpea in Andhra Pradesh. Indian J. Plant Prot., 42, 324-332 (2014).

Sharma, H. C.: Heliothis and Helicoverpa management: Emerging trends and strategies for future research (Ed.: H.C. Sharma) Oxford \& IBH publishing Co. Pvt. Ltd., New Delhi (2015).

Sharma, K., R. K. Sharma, S. Chander and V. Jilu: Effects of weather parameters on guava fruit fly (Bactrocera zonata) population at IARI, New Delhi. J. Agrometeorol., 17, 227-229 (2015).

Sharma, P. K., U. Kumar, S. Vyas, S. Sharma and S. Shrivastava: Monitoring of Helicoverpa armigera (Hubner) (Lepidoptera: Noctuidae) through pheromone traps in chickpea (Cicer arietinum) crop and influence of some abiotic factors on insect population. $J$. Environ. Sci. Toxicol. Food Technol., 1, 44-46 (2012).

Siswanto, M. Rita, O. Dzolkhifli and K. Elna: Population fluctuation of Helopeltis antonii Signoret on cashew Anacardium occidentalle L. in Java Indonesia. Pertanika J. TropicalAgric. Sci., 31,191-196 (2008).

Willmott, C. J.: Some comments on the evaluation of model performance. Bull. Am. Meteorol. Soc., 63, 1309-1313 (1982). 